Thomas Elbert · Annette Sterr · Herta Flor

Brigitte Rockstroh · Stefan Knecht - Christo Pantev

Christian Wienbruch · Edward Taub

\title{
Input-increase and input-decrease types of cortical reorganization after upper extremity amputation in humans
}

\begin{abstract}
A plastic remodeling of regions in somatosensory cortex has previously been observed to occur in separate experimental paradigms in response to loss of somatosensory input and to increase in input. In this study, both types of cortical reorganization have been observed to occur concurrently in the same adult human nervous system as a result of a single intervention. Following upper extremity amputation, magnetic source imaging revealed that tactile stimulation of the lip evoked responses not only in the area of the somatosensory cortex corresponding to the face, but also within the cortical region that would normally correspond to the now absent hand. This "invasion" of the cortical amputation zone was accompanied by a significant increase in the size of the representation of the digits of the intact hand, presumably as a result of an increased importance of sensory stimulation consequent to increased dependence on that hand imposed by the loss of the contralateral extremity.
\end{abstract}

Key words Somatosensory - Cortex · Plasticity · Amputation · Magnetoencephalography

\section{Introduction}

Modulation in the flow of somatosensory input has been shown to be followed by changes in the cortical represen-

T. Elbert () ) · A. Sterr · B. Rockstroh - C. Wienbruch University of Konstanz, Postfach 5560-d23,

D-78464 Konstanz, Germany

Fax: +49-7531-88-2891,

e-mail: thomas.elbert@uni-konstanz.de

H. Flor

Humboldt-University, Hausvogteiplatz 5-7,

D-10117 Berlin, Germany

S. Knecht · C. Pantev

University of Münster, Kardinal-von Galen-Ring 10,

D-48129 Münster, Germany

E. Taub

University of Alabama at Birmingham, 415 Campbell Hall,

Birmingham, AL 35294-1170, USA tation of the body in the somatosensory cortex. In owl monkeys, prolonged behaviorally relevant stimulation has been found to lead to an expansion in the cortical representation of the stimulated part of the body (Jenkins et al. 1990; Recanzone et al. 1992a,b,c; Florence and Kaas 1995). Magnetic source imaging (MSI) has provided evidence that use-dependent reorganization also occurs in humans (Elbert et al. 1995; Rockstroh et al. 1996). String players, for example, provide a model for the effects of differential afferent input to the two hemispheres. It was found that the digits of the left hand, which engage in fingering the strings, had a larger representation than those of the right hand and also a larger representation than the left-hand fingers of nonmusician controls (Elbert et al. 1995).

Loss of sensory input also brings about changes in the representation of the body in the somatosensory cortex. In macaque monkeys, Pons and coworkers (1991) reported massive reorganization of primary somatosensory cortex (in area $3 b$ ) subsequent to sensory deafferentation of an entire arm 12 years earlier. The adjacent representation of the face had expanded into the hand and arm areas so that stimulation of the face evoked activity in the area formerly occupied by the representation of hand and digits. Extensive cortical reorganization following somatosensory deafferentation also occurs and persists in humans following upper extremity amputation, as demonstrated by MSI (Elbert et al. 1994; Yang et al. 1994; Flor et al. 1995; Knecht et al. 1996). The magnitude of cortical reorganization is strongly associated with the amount of phantom limb pain experienced by the amputees (Flor et al. 1995). Furthermore, cortical reorganization is probably related to tinnitus, which has been characterized as a type of auditory phantom sensation and which is often associated with injury within the cochlea, i.e., loss of auditory input (Mühlnickel et al. 1996).

In amputees, there is not only loss of sensory input from the amputated limb, but a probable increase of afferent input from the paired intact limb due to the increased use required by the loss of the contralateral extremity. Thus, in addition to the "invasion" of the cortical ampu- 
tation zone that has been demonstrated to occur in the somatosensory cortex opposite the amputation, there should also be a corresponding expansion of the cortical representation of the intact arm. The present experiment was designed to test this possibility. Using MSI, the representations of digits D1 (thumb) and D5 (little finger) of the intact hand of unilateral upper extremity amputees were compared with those of controls.

\section{Materials and methods}

Six upper extremity amputees (two with left, four with right arm amputation; all right-handed before the amputation; mean age 48 years,) and six adult right-handed control subjects participated in the study. The subjects ranged in age from 18 to 55 years at the time of amputation (mean 27 years); amputation had occurred 2-49 years (mean 21 years) prior to the current investigation (see Table 1).

Somatosensory stimulation was delivered separately to the first and fifth digits of the hand (both hands in controls) and to the lower lip at both corners of the mouth. The stimulation consisted of a brief, nonpainful superficial pressure stimulus delivered through a pneumatic device. One thousand stimuli were given at each of the stimulation sites (first and fifth digits, left and right corners of the lower lip) at an average rate of $0.5 \mathrm{~Hz}$. The interval between stimulus onsets varied randomly between 450 and $550 \mathrm{~ms}$. The sequence of stimulation sites was balanced across subjects. The sensor array of magnetic detectors (BTi Magnes 37-channel biomagnetometer) was positioned over the hemisphere (centered over C3 or C4) contralateral to the stimulated limb and lip sites. Data were filtered with a bandpass of $0.01-100 \mathrm{~Hz}$ and sampled at a rate of $520.5 \mathrm{~Hz}$. A response was omitted from the average if its range exceeded $2 \mathrm{pT}$ in any of the MEG channels.

A first major peak was identified in each of the evoked waveforms within the time window of 30-75 ms (Fig. 1). For this peak, a single equivalent current dipole (ECD) model (using the best fitting local sphere) was fitted to the measured field distribution and the medians of the dipole moment and the dipole location were computed from a selection of contiguous time points within a 20-ms time segment (11 sampling points) around the maximal root mean square (RMS) across the 37 channels. Points were selected if they met the following criteria: (1) RMS indicating a signal-to-noise ratio $>3$, (2) goodness of fit of the ECD model to the measured field $>0.95$, and (3) a minimal confidence volume of the ECD location $<300 \mathrm{~mm}^{3}$.

The representations of face and hand in area $3 \mathrm{~b}$ of controls was compared in amputees with the representation of the face in the hemisphere contralateral to the amputation and with the face and hand areas in the hemisphere contralateral to the intact arm. The following Euclidean distances were calculated: lip-D1, lip-D5, and D1-D5. To evaluate the changes in lip and hand representations, if any, due to amputation, distances and dipole moments in both hemispheres were averaged for the controls and compared with those parameters of (a) the hemisphere contralateral to the amputa- tion and (b) the hemisphere contralateral to the intact arm. One-factor analyses of variance were used to compare the above measures for amputees versus controls. Post-hoc analyses were carried out by means of t-tests.

\section{Results}

A typical example of averaged evoked fields in a single subject is presented in Fig. 1. There was no obvious difference in waveshape between amputees and controls. In all subjects the location for the maximal evoked field for D1 was inferior (lateral along the surface of the cortex) as compared with the location of the peak for D5.

The (three-dimensional) Euclidean distance between the cortical representations of D1 and D5 was used to estimate the size of the cortical hand representation. The intact hand in amputees encompassed a larger area $(12.4 \pm 5.5 \mathrm{~mm})$ than the D1-D5 difference averaged across both hands in controls $(7.0 \pm 1.5 \mathrm{~mm}, \mathrm{t}=2.4$, $\mathrm{P}<0.05)$. Moreover, as may be seen in the coronal section presented in Fig. 2, the average D1-D5 difference, along the surface of the cortex (lateral-medial) was larger in amputees than in controls $(\mathrm{t}=3.2, \mathrm{P}<0.01)$. When compared with the cortical representations in control subjects, only the D1 representation in the amputees had shifted significantly along the central sulcus (Fig. 2). The Euclidean

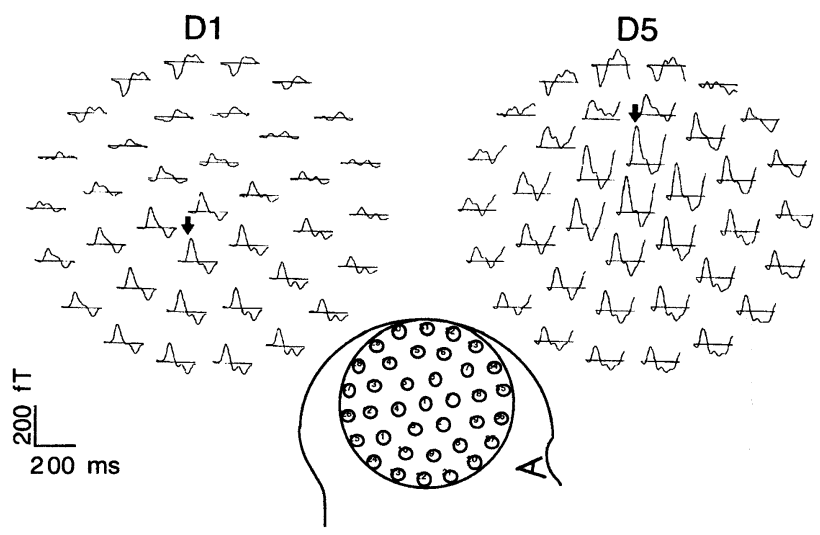

Fig. 1 Set of waveforms indicating the magnetically evoked responses averaged for left thumb (D1, left of figure) and left little finger (D5, right of figure), respectively, of a control subject. The arrows mark the first major peak chosen for dipole modeling. The lower insert represents the sensor array placement

Table 1 Demographic data and expansion of finger area in amputees

\begin{tabular}{|c|c|c|c|c|c|c|}
\hline $\begin{array}{l}\text { Age } \\
\text { (years) }\end{array}$ & $\begin{array}{l}\text { Age at } \\
\text { amputation }\end{array}$ & $\begin{array}{l}\text { Chronicity } \\
\text { (years) }\end{array}$ & $\begin{array}{l}\text { Side and site } \\
\text { of amputation }\end{array}$ & $\begin{array}{l}\text { Length of } \\
\text { stump }(\mathrm{cm})\end{array}$ & Cause & $\begin{array}{l}\text { Distance } \\
\text { D1-D5 }(\mathrm{cm})^{\mathrm{a}}\end{array}$ \\
\hline 68 & 19 & 49 & Right, above elbow & 10 & Accident (shell splinter) & 1.1 \\
\hline 57 & 55 & 2 & Right, above wrist & 40 & Osteosarcoma & 1.4 \\
\hline 27 & 22 & 5 & Left, below elbow & 30 & Accident (traffic) & 0.9 \\
\hline 32 & 28 & 4 & Right, above elbow & 9 & Accident (work) & 2.0 \\
\hline 34 & 20 & 14 & Right, above wrist & 43 & Accident (traffic) & 0.4 \\
\hline
\end{tabular}

${ }^{a}$ Distance D1-D5 for control subjects $(\mathrm{cm})$ : average across both hemispheres: $0.70 \pm 0.15$, right hand stimulation: $0.70 \pm 0.39$, left hand stimulation: $0.72 \pm 0.25$ 


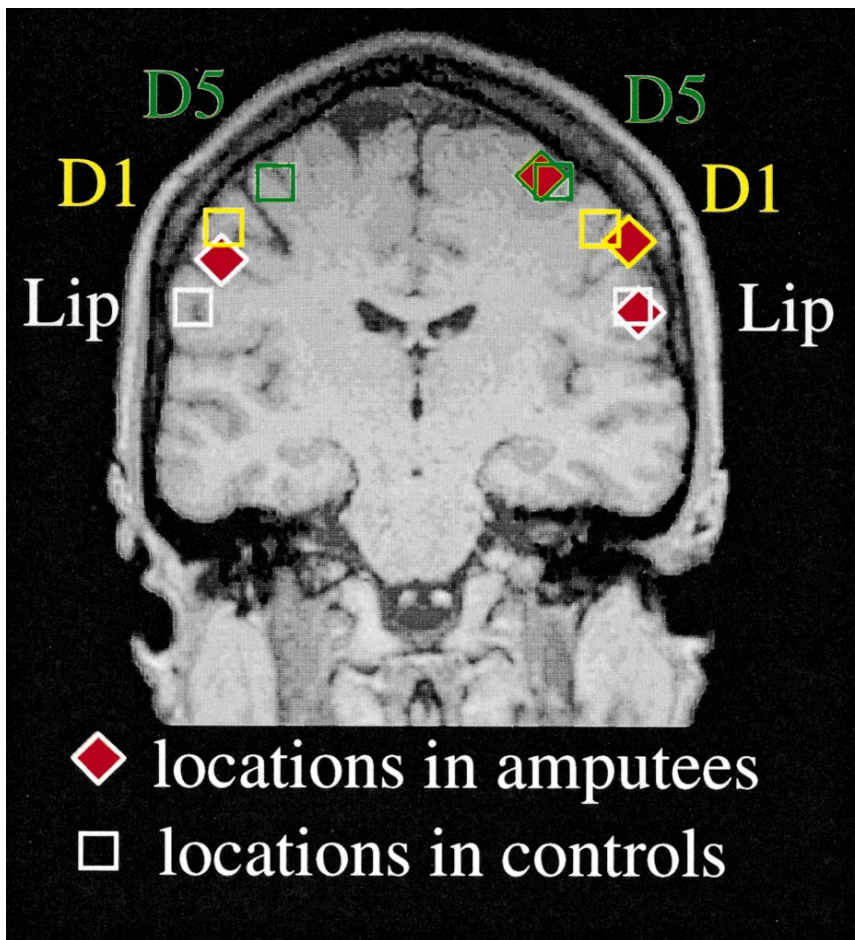

Fig. 2 Schematic locations of the equivalent current dipoles (ECD) for D1, D5, and lip stimulation seen here as projections onto a coronal MR slice of one control subject. Open squares indicate the locations for controls (averaged across subjects and hemispheres); filled diamonds represent average locations for arm amputees. For the amputees, the left side of the figure shows the lip representation in the hemisphere opposite the affected side; the right side of the figure shows lip and digit locations contralateral to the intact side. The lip location on the amputation side in amputees has shifted relative to the controls. Contralateral to the intact side, the hand area of amputees has expanded, compared with controls, as a result of a shift in D1 location. [The amputation affected arms on different sides of the body (two left, four right); consequently, the data for the controls were averaged for left and right hemispheres, and are presented here bilaterally]

distance between the representations of lip and D5 was $5.6 \mathrm{~mm}$ greater in amputees than in control subjects $(\mathrm{t}=2.6, \mathrm{P}<0.05)$, again indicating that there had been an expansion in the intact hand area of amputees. The distance between lip and D1, the finger representation closest to the lip, did not decrease significantly in amputees as compared with controls. There was also no group difference in the magnitude of the dipole moments of the digits (F-ratios for main effect or interaction $<2.5$ ). The increase in D1-D5 distance was not significantly correlated with chronicity at the time of measurement (Euclidean D1-D5 distance vs chronicity, $r=0.05$ ) or age at amputation (regression with Euclidean distance, $r=0.22$ ).

In the hemisphere opposite to the amputated arm, the cortical representation of the lip had shifted in a superior direction $(13.9 \mathrm{~mm}, \mathrm{t}=2.9, \mathrm{P}<0.01)$ compared with controls (Fig. 2), as had been described in previous reports (Elbert et al. 1994). The location of the representation of the lip contralateral to the intact side corresponded to the location of the lip representation in control subjects.

\section{Discussion}

The results of the present experiment are of interest because they demonstrate that the two different types of cortical reorganization that have been reported in the literature can occur in response to a single intervention. The decrease in sensory input produced here by upper extremity amputation was followed by an "invasion" of the cortical amputation zone by the adjacent face area whose innervation had remained intact, as had been demonstrated previously in monkeys (Jenkins et al. 1990; Pons et al. 1991; Recanzone et al. 1992b,c; Florence and Kaas 1995) and humans (Elbert et al. 1994; Yang et al. 1994; Flor et al. 1995; Knecht et al. 1996) In addition, the distance between the cortical representations of the digits (D1 and D5) of the intact hand in amputees was increased compared with the control subjects, suggesting an increase in the representation of the intact hand. This change could be due to an increased importance of sensory stimulation consequent to the increased dependence on that hand imposed by the loss of the amputated hand. Moreover, the shift was more pronounced for D1 than for D5, which could reflect a difference in the frequency of use between the thumb and little finger. Use-dependent increases in the somatosensory homuncular representation of body parts have previously been demonstrated in monkeys (Jenkins et al. 1990; Recanzone et al. 1992b,c) and humans (Elbert et al. 1995; Rockstroh et al. 1996). Consequently, the results for the hemisphere opposite the intact arm provide additional evidence in support of the view that the organization of the human brain is usedependent and continuously adapts to the current needs and experiences of the individual.

It is likely that the processes taking place in the two hemispheres were separate from one another since, in terms of the topography of the somatosensory cortex, they have opposing directionality, i.e., an invasion of the digit representation by the cortical face area versus an expansion of the representation of the digits. Transfer of either of these effects across the corpus callosum (Calford and Tweedale 1990)would result in an interference of the process taking place in the other hemisphere.

A plastic remodeling of cortex in response to both loss of input and increased input have been observed to occur here contemporaneously in the same nervous system. Both phenomena have been termed cortical reorganization, but one of the central issues in this area of study is whether both in fact involve the same mechanisms. The two processes mentioned most frequently in past discussions of this question are sprouting from neighboring intact neural elements and unmasking of previously silent synaptic connections. To these can be added deafferentation hyperexcitability in the case of loss of afferent input (Taub et al. 1995; Knecht et al. 1996). The extent to which these, and possibly other as yet unknown, mechanisms contribute to the emergence of input-increase and input-decrease types of cortical reorganization in the adult nervous system, and whether these processes are different 
shortly after intervention and at a later time, are important issues that await resolution by future research.

Acknowledgements This work was supported by grants from the Deutsche Forschungsgemeinschaft and presented in part at the Tenth International Conference on Biomagnetism, Santa Fe, 1996.

\section{References}

Calford M, Tweedale R (1990) Interhemispheric transfer of plasticity in the cerebral cortex. Science 249:805-807

Elbert T, Flor H, Birbaumer N, Knecht S, Hampson S, Larbig W, Taub E (1994) Extensive reorganization of the somatosensory cortex in adult humans after nervous system injury. Neuroreport 5:2593-2597

Elbert T, Pantev C, Wienbruch C, Rockstroh B, Taub E (1995) Increased use of the left hand in string players associated with increased cortical representation of the fingers. Science 220:21-23

Flor H, Elbert T, Knecht S, Wienbruch C, Pantev C, Birbaumer N, Larbig W, Taub E (1995) Phantom limb pain as a perceptual correlate of massive reorganization in upper limb amputees. Nature 375:482-484

Florence SL, Kaas JH (1995) Large-scale reorganization at multiple levels of the somatosensory pathway follows therapeutic amputation of the hand in monkeys. J Neurosci 15:8083-8095

Jenkins WM, Merzenich MM, Ochs MT, Allard T, Guíc-Robles E (1990) Functional reorganization of primary somatosensory cortex in adult owl monkeys after behaviorally controlled tactile stimulation. J Neurophysiol 63:82-104

Knecht S, Henningsen H, Elbert T, Flor H, Höhling C, Pantev C, Taub E (1996) Reorganizational and perceptual changes after amputation. Brain 119:1213-1219
Mühlnickel W, Elbert T, Taub E, Flor H (1996) Deviations from the tonotopic map are correlated with tinnitus strength. In: Woods CC, Okada Y (eds) Proceedings of the tenth international conference on biomagnetism, Santa Fe, pp 275-276

Pons TP, Garraghty AK, Ommaya AK, Kaas JH, Taub E, Mishkin M (1991) Massive cortical reorganization after sensory deafferentation in adult macaques. Science 252:1857-1860

Raussell E, Cusick CG, Taub E, Jones GE (1992) Chronic deafferentation in monkeys differentially affects nociceptive and nonnociceptive pathways distinguished by specific calcium-binding proteins and down-regulates g-aminobutyric acid type A receptors at thalamic levels. Proc Natl Acad Sci USA 89:2571-2575

Recanzone GH, Jenkins WM, Merzenich MM (1992a) Progressive improvement in discriminative abilities in adult owl monkeys performing a tactile frequency discrimination task. J Neurophysiol 67:1015-1030

Recanzone GH, Merzenich MM, Jenkins WM (1992b) Frequency discrimination training engaging a restricted skin surface results in an emergence of a cutaneous response zone in cortical area 3a. J Neurophysiol 67:1057-1070

Recanzone GH, Merzenich MM, Jenkins WM, Grajski A, Dinse HR (1992c) Topographic reorganization of the hand representation in area $3 \mathrm{~b}$ of owl monkeys trained in a frequency discrimination task. J Neurophysiol 67:1031-1056

Rockstroh B, Vanni S, Elbert T, Hari R (1996) Extensive somatosensory stimulation alters somatosensory evoked fields. In: Woods CC, Okada Y (eds) Proceedings of the tenth international conference on biomagnetism, Santa Fe, pp 84-88

Taub E, Flor H, Knecht S, Elbert T (1995) Correlation between phantom limb pain and cortical reorganization. J NIH Res 7:49-50

Yang TT, Gallen CC, Ramachandran VS, Cobb S, Schwartz BJ, Bloom FE (1994) Noninvasive detection of cerebral plasticity in adult human somatosensory cortex. Neuroreport 5:701-704 